\title{
Nota sobre "Rutas migratorias y nuevos espacios de frontera: el caso de las Islas Canarias”, ponencia presentada por Ana María López*
}

\section{Maritza Caicedo Riascos**}

La ponencia presentada por Ana María López "Rutas migratorias y nuevos espacios de frontera: el caso de las Islas Canarias" ofrece un panorama global de la migración en Islas Canarias en el que confluyen aspectos históricos, políticos y económicos que ayudan a explicar los movimientos de población en esta región de Europa. Su trabajo habla del proceso migratorio de la Europa Mediterránea y del sur del continente europeo a lo largo de las tres últimas décadas, y se destacan en el caso concreto de la migración en las Islas Canarias aspectos relacionados con la modificación de los flujos migratorios, la feminización del proceso migratorio y una creciente participación de inmigrantes de origen latinoamericano, el crecimiento de la inmigración irregular o indocumentada y la creación en años recientes de una agenda política para hacer frente a este fenómeno.

La dinámica migratoria en las Islas Canarias ha sufrido cambios trascendentales en las últimas décadas. En primer lugar, Canarias ha pasado de ser centro de emigración hacia otros países de Europa e incluso hacia a América a ser un país receptor de población inmigrante especialmente de África y de manera cada vez más creciente de América Latina. Esto sin duda -como lo señala la autora- está relacionado con aspectos socioeconómicos, tales como el crecimiento de la economía y la segmentación de los mercados de trabajo que cada vez demandan más personal con bajos niveles de calificación para realizar labores precarias que la población nativa ya no desea. ${ }^{1}$

* La ponencia de Ana María López fue presentada en el Seminario Permanente sobre Migración Internacional, organizado por El Colegio de México, El Colegio de la Frontera Norte, la Sociedad Mexicana de Demografía y la organización Sin Fronteras, Tijuana, 5 de noviembre de 2004.

** Estudiante del doctorado en Estudios de Población de El Colegio de México. Correo electrónico: mcaicedo@colmex.mx.

${ }^{1}$ Sartori (2001: 139) además agregaría que Europa ha pasado de ser un continente exportador de migrantes a ser importador de inmigrantes, primero porque los europeos han llegado a ser ricos y ni siquiera los europeos pobres quieren realizar los trabajos "humildes, degradantes y pesados", y segundo porque los subsidios de desempleo permiten a los europeos vivir sin trabajar.

ESTUDIOS DEMOGRÁFICOS Y URBANOS, VOL. 20, NÚM. 2 (59), PP. 387-393 
La característica fundamental de estos empleos es que ofrecen salarios bajos y mantienen a los trabajadores en condiciones de alta precariedad laboral, dado que son de carácter inestable, de tiempo parcial, generalmente sin prestaciones sociales y no otorgan al trabajador la posibilidad de hacer carrera o crecer por medio del empleo.

Los empleadores en los países de acogida necesitan trabajadores que estén dispuestos a recibir bajas remuneraciones para no tener que aumentar los salarios en toda la jerarquía ocupacional, y necesitan trabajadores que no vean el empleo como una posibilidad por medio de la cual puedan tener un reconocimiento o mejorar su estatus social. Esto es lo que Piore (1979: 229) llama respectivamente inflación estructural y problemas motivacionales, que hacen que los inmigrantes sigan siendo deseados para desempeñar este tipo de trabajos en los países desarrollados.

Por otro lado, la vinculación de los trabajadores inmigrantes con este tipo de trabajos en algunos países del sur de Europa se ha visto favorecida por la existencia de un sistema de cuotas que permite el ingreso de inmigrantes para ser parte de la fuerza laboral. Con esto los gobiernos reconocen la necesidad de trabajadores extranjeros para suplir la baja participación de los nativos en este tipo de tareas (Mendoza, 1999). Por otro lado, para los inmigrantes de países en desarrollo el ingreso a estos mercados de trabajo constituye la posibilidad de que su grupo doméstico pueda mejorar sus condiciones de vida, ya que los salarios que perciben en los países de acogida son superiores a los que pueden ganar en sus lugares de origen, así cuenten con altos perfiles ocupacionales.

En segundo lugar, la inmigración a las Islas Canarias ha experimentado un proceso de feminización de los flujos provenientes especialmente de América Latina. Un trabajo realizado por Martínez (2003) sobre la migración latinoamericana a España entre 1999 y 2001 menciona que esta inmigración ha estado caracterizada por un fuerte predominio de las mujeres. El índice de masculinidad entre la población inmigrante de origen latinoamericano para el año 1999 fue de 54 hombres por cada 100 mujeres, para el año 2000 fue de 60 y para el 2001 fue de 73 hombres por cada 100 mujeres. Aunque estos datos muestran una tendencia creciente de hombres latinoamericanos en el stock de inmigrantes en España, dejan clara la fuerte presencia de las mujeres en la inmigración española.

La observación de este fenómeno desde el sitio de llegada permite pensar que la creciente presencia de mujeres de países periféricos 
en los países centrales o desarrollados responde a una importante demanda de fuerza laboral femenina para llevar a cabo trabajos del ámbito reproductivo que las mujeres nativas han dejado de realizar, dado el aumento de su nivel de calificación para el trabajo. Estas tareas están relacionadas con el servicio doméstico, el cuidado de niños y ancianos e incluso la prostitución.

Sassen (1999: 120) asegura que en la última década se ha incrementado la presencia de mujeres en circuitos transfronterizos, ya que éstos son rentables y proporcionan beneficios a particulares a costa de las condiciones de desventaja en que se encuentran las migrantes. Estos circuitos, según la autora, incluyen la industria del sexo y distintos tipos de trabajo en los mercados formal e informal, así como migraciones transfronterizas que sean de carácter documentado o no constituyen un aporte importante para las economías tanto de los países emisores como de los receptores.

La autora explica que estos circuitos pueden constituirse en indicadores parciales de la feminización de la supervivencia, ya que cada vez más estas formas de sustento, de obtención de beneficios y de garantizar ingresos para las diferentes naciones se realizan a costa de las mujeres. Para Sassen uno de los factores que han contribuido a la creciente salida de mujeres de sus países de origen y su vinculación a estos circuitos ha tenido que ver con el crecimiento de la deuda externa de los países en desarrollo en los últimos años, ya que por un lado el pago de la deuda y la adopción de programas de ajuste estructural han afectado el desarrollo de programas estatales destinados a las mujeres, especialmente en los ámbitos de salud y educación y por otro lado, han aumentado el desempleo debido también a la austeridad presupuestaria. Esto, sin duda alguna, ha coadyuvado a que las mujeres busquen otras estrategias que garanticen su supervivencia y la de sus familias, tales como el empleo informal, la migración y la prostitución entre otras posibles.

Aunque el trabajo de López exploró tangencialmente el problema de la migración femenina en las Islas Canarias y en el sur de Europa, logró despertar inquietud en torno a un tema al que no se le ha otorgado la merecida importancia en el actual contexto de globalización en donde el fenómeno migratorio tiende a generalizarse cada vez más, y con él, a una escala menor, la movilidad y el tráfico de mujeres.

La prostitución o los servicios sexuales constituyen una actividad económica en la que cada vez más participan mujeres inmigrantes. Este trabajo lo deben realizar en total desprotección porque en algunos 
países su ejercicio está prohibido para las mujeres inmigrantes; esto las hace víctimas de organizaciones criminales que se encargan de colocarlas bajo condiciones infrahumanas. Son víctimas de maltratos físicos, psicológicos, abusos sexuales e incluso frecuentemente se les impide el uso de métodos para prevenir infecciones de transmisión sexual como el sida (Sassen, 1999). Un informe de la OIM especifica que $75 \%$ de las mujeres que ejercen la prostitución en Alemania son extranjeras y $80 \%$ en Italia (Sassen, 2003: 120).

Esto lleva a cuestionar la dualidad propia de las sociedades desarrolladas, en donde coexisten segmentos de población con buenos empleos y condiciones de vida favorables al lado de personas que experimentan distintas formas de marginación y exclusión social que las convierten en "ciudadanos de segunda categoría". Se dice que las sociedades desarrolladas han alcanzado un mayor estado del bienestar para su población, y esto ha tenido que ver, además del desarrollo económico y el avance tecnológico, con el establecimiento de políticas de equidad social. En tal contexto cabe preguntar si es pertinente hablar de derechos humanos y de un mayor estado de bienestar para los inmigrantes en estas sociedades.

Pensando en función del género, ¿se podría describir como un proceso emancipatorio y de empoderamiento el hecho de que las mujeres de los países del tercer mundo dejen sus lugares de origen y se vinculen en los circuitos migratorios que hemos mencionado? Posiblemente a muchas de ellas la salida de sus lugares de origen les signifique un mayor sentido de libertad y autonomía, así como el reconocimiento de éxito dentro de sus comunidades por haber obtenido logros económicos que no todas las mujeres han alcanzado.

Visto desde otra óptica podría sonar absurdo que el desarrollo de las actividades "reproductivas", a las que generalmente se otorga una baja valoración social -y en especial en las condiciones en que las realizan gran parte de las mujeres inmigrantes en los países de acogida-, pueda permitir a las que nacieron allí la emancipación que han logrado. Cuando en las sociedades receptoras las inmigrantes no son vistas como sujetos de derecho es imposible hablar de su emancipación y empoderamiento.

El otro aspecto que destaca en la ponencia es el incremento de la inmigración indocumentada a las Islas Canarias. Según López, una parte importante de la inmigración irregular o indocumentada en este lugar se da desde las fronteras con el continente africano y a partir de los años noventa por el Estrecho. Éste es un aspecto importante sobre 
el que vale la pena detenerse un poco, dadas las serias implicaciones que tiene la inmigración indocumentada tanto para los inmigrantes como para los países de acogida.

Los inmigrantes indocumentados en los países de acogida difícilmente pueden ejercer a plenitud sus derechos ciudadanos y en especial sus derechos laborales. En Estados Unidos, por ejemplo, es claro que existen derechos laborales inalienables para los trabajadores, pero cuando se trata de inmigrantes sin autorización para permanecer y trabajar en ese país, las posibilidades de hacer valer los derechos que los protegen y les otorgan cierta capacidad de negociación ante el mercado de trabajo se reducen ostensiblemente, convirtiéndolos en materia vulnerable frente a los empleadores y a la sociedad en general.

Sin embargo, en altas condiciones de precariedad laboral el trabajo inmigrante indocumentado ha constituido un aporte importante para las economías de los países desarrollados. Por ejemplo, en Estados Unidos en épocas de recesión económica el trabajo inmigrante, y en especial el indocumentado, ha ayudado a mantener en niveles bajos la inflación debido a que una parte importante de los inmigrantes en ese país trabaja por bajos salarios (Levine, 2001: 199). En el caso de las Islas Canarias este tipo de inmigración también ha constituido un aporte importante para la economía, y sin embargo los trabajadores se han mantenido en condiciones de precariedad laboral.

Según la expositora, la creciente migración indocumentada a estas islas ha provocado una respuesta política del gobierno canario que se ha limitado fundamentalmente a proteger las zonas fronterizas mediante el establecimiento de políticas migratorias que han tenido consecuencias lamentables, tales como la muerte de inmigrantes africanos que intentan cruzar la frontera en forma no autorizada. La experiencia del control fronterizo entre México y Estados Unidos muestra que estas estrategias unilaterales no constituyen una solución para el problema de la inmigración. Distintos factores de orden macro o microsocial siguen motivando los movimientos transfronterizos, que difícilmente pueden ser frenados únicamente por las acciones de los estados de atracción.

Por un lado, el creciente movimiento de la población responde a cambios estructurales en las economías de los países desarrollados y del tercer mundo y a la globalización que los conecta por medio del capital. Sin embargo no deja de verse la gran contradicción que plantean los procesos globalizadores. Se ha dado al mercado la capacidad de incidir en todos los ámbitos de la vida social de los países; es decir, 
cada vez más los procesos de toma de decisiones se realizan en instituciones financieras internacionales que imponen el tipo de política económica que deben seguir los estados. Esto sin lugar a dudas resta poder a los estados para decidir sobre el destino de las naciones.

Por otro lado, los países sí ejercen su soberanía cuando se trata del control migratorio y establecen políticas que en lugar de disminuir o frenar los flujos migratorios mantienen un alto grado de vulnerabilidad social y económica en quienes logran cruzar las fronteras.

El tema tratado en la ponencia estimula la necesidad de seguir generando conocimiento en torno al problema de la migración internacional y pone de relieve dos puntos clave a considerar en el análisis del fenómeno: el primero tiene que ver con la vinculación de la perspectiva de género en el estudio de la migración internacional, dado que, como se mencionó en la ponencia, la participación de las mujeres en los procesos migratorios es creciente y su desplazamiento obedece cada vez más a la búsqueda de empleos que logren garantizar mejores condiciones de vida para su grupo doméstico.

El segundo aspecto está relacionado con la necesidad de idear y emprender acciones que lleven a una verdadera globalización de la fuerza de trabajo. Esto es, restar las restricciones a la movilidad de la fuerza de trabajo tal y como se ha hecho con otros factores productivos como el capital y las mercancías. Sin duda alguna el libre acceso de los inmigrantes al mercado laboral de los países desarrollados ayudaría a disminuir las condiciones de vulnerabilidad en que se encuentran muchos trabajadores inmigrantes y evitaría la muerte de muchas personas que intentan ingresar a estos países en condiciones de alto riesgo.

\section{Bibliografía}

Levine, Elaine (2001), Los nuevos pobres de Estados Unidos: los hispanos, México, UNAM.

Martínez, Raquel (2003), "La reciente inmigración latinoamericana a España”, Santiago de Chile, CELAdE/División de Población de la CEPAL (Población y Desarrollo, 40).

Mendoza, Cristóbal (1999), "Migración y mercados de trabajo en el sur de Europa: inserción laboral de los trabajadores africanos en España”, Frontera Norte, vol. 11, núm. 21, pp. 95-116.

Piore, Michael (1979), Birds of Passage: Migrant Labor in Industrial Societies, Cambridge, Cambridge University Press. 
Sartori, Giovanni (2001), La sociedad multiétnica, pluralismo, multiculturalismo y extranjeros, Madrid, Tauros.

Sassen, Saskia (2003), Contrageografías de la globalización, género y ciudadanía de los circuitos transfronterizos, Madrid, Traficantes de Sueños.

(1999), "Strategic Instantiation of Gendering in the Global Economy", en Charles Hirschman, Philip Kasinitz y Josh De Wind (eds.), The Handbook of International Migration: the American Experience, Nueva York, Russell Sage Foundation, pp. 43-59. 